\title{
Development of a seismic processing sequence 2D seismic procedure observations ( on an example of Olhivska area).
}

\author{
*A. Lomonos (Taras Shevchenko National University of Kyiv) \\ SUMMARY
}

Seismic processing sequence 2D seismic grids in Focus (Paradigm):

1. Data entry seismic observations in RAW format in the project, creating job file in format DSK.

2. Calculation of the location of the coverage CDP on curved profiles, entering them into a database (the program CDPLINE).

3. The choice of profiles and assigning the track geometry seismic observations 2D (programs COLLECT, PROFILE).

4. Manually editing of data (EDIT, IEDIT).

5. Definition of a priori kinematic corrections (DEFINE).

6. Calculation of initial static corrections determined by the relief +100 meters (DATUMS).

7. The amount of the initial static and kinematic corrections in an open channel (NMO, MUTE, AGC, STACK).

8. Calculation of priori static corrections by the method of refracted waves to bring the level of 100 $\mathrm{m}$ (programs FBNET, REFSOL).

9. The amount of a priori static corrections calculated by the method of refracted waves in an open channel (NMO, MUTE, AGC, STACK).

10. Preprocessing seismograms - editing tracks with a high level of noise entering a priori static corrections, relaxation constant component runs, recovery enhancement amplitudes based on spherical divergence, conservation values in the header seismic database, calculation of the logarithms of the energy spectra of runs, the calculation of binary multiplicity of overlapping (EDIT program , IEDIT, QUIXTAT, DEBIAS, GAIN, HDRMATH, SURFAN).

11. Surface-consistent amplitude equalization, predictive deconvolution, filtering angles to eliminate regular waves, interference, regulation seismograms, balancing, sort by BHT (SURFAMP, DECONA, TSCALE, LFAF, DESCLE, AMPSCAL, SUPPRES, DEBIAS, ENSEQU, BALANCE, SORT ).

12. The first sum after deconvolution of the a priori parameters of static and kinematic corrections (NMO, MUTE, AGC, STACK).

13. he first analysis of kinematic corrections (AGC, MUTE, VELDEF).

14. The amount after the first correction kinematic corrections (NMO, MUTE, AGC, STACK).

15. The first correction surface-coordinated static corrections (NMO, MUTE, AGC, PREPARE, STATICR). 
16. The amount of correction after the first surfactant coordinated static corrections (QUIXTAT, NMO, MUTE, AGC, STACK).

3 analyzes of the kinematic corrections was performed.

17. At the end of processing was performed post-stack Kirchhoff Time Migration 2D seismic sections (MIGTX).

\section{Розробка графу обробки методикою 2D сейсмічних спостережень (на прикладі Ольхівської площі)}

*A.І. Ломонос (Київський національний університет імені Тараса Шевченка) PEЗЮME

Послідовність графу обробки профілів 2D в системі Focus (Paradigm):

1. Введення даних сейсмічних спостережень в форматі RAW в проект, створення робочих файлів в форматі DSK.

2. Розрахунок місця положення та кратності СГТ на криволінійних профілях, занесення їх в базу даних (програма CDPLINE).

3. Вибір профілів та присвоєння сейсмічним трасам геометрії спостережень 2D (програми COLLECT, PROFILE).

4. Ручне редагування даних (EDIT, IEDIT).

5. Визначення апріорних кінематичних поправок ( DEFINE).

6. Розрахунок початкових статичних поправок визначених за рельєфом, для рівня приведення $+100 \mathrm{M}$. (DATUMS).

7. Сума з початковими статичними і кінематичними поправками на відкритому каналі (NMO, MUTE, AGC, STACK).

8. Розрахунок апріорних статичних поправок за методом заломлених хвиль, для рівня приведення +100м (програми FBNET, REFSOL).

9. Сума з апріорними статичними поправками розрахованими за методом заломлених хвиль на відкритому каналі (NMO, MUTE, AGC, STACK).

10. Попередня обробка сейсмограм - редагування трас з високим рівнем шумів, введення апріорних статичних поправок, послаблення постійної складової траси, відновлення підсилення амплітуд з урахуванням сферичного розходження, збереження значень заголовків в сейсмічній базі даних, розрахунок логарифмів енергетичних спектрів трас, розрахунок 
бінарної кратності перекриття (програми EDIT, IEDIT, QUIXTAT, DEBIAS, GAIN, HDRMATH, SURFAN).

11. Поверхнево-узгоджене вирівнювання амплітуд, прогнозуюча деконволюція, фільтрація по кутам нахилу для усунення регулярних хвиль-завад, нормування сейсмограм, балансування, сортування по СГT (SURFAMP, DECONA, TSCALE, LFAF, DESCLE, AMPSCAL, SUPPRES, DEBIAS, ENSEQU, BALANCE, SORT).

12. Перша сума після деконволюції з апріорними параметрами статичних і кінематичних поправок (NMO, MUTE, AGC, STACK).

13. Перший аналіз кінематичних поправок (AGC, MUTE, VELDEF).

14. Сума після першої корекції кінематичних поправок (NMO, MUTE, AGC, STACK).

15. Перша корекція поверхнево-узгоджених статичних поправок (NMO, MUTE, AGC, PREPARE,STATICR).

16. Сума після першої корекції поверхнево-узгоджених статичних поправок (QUIXTAT, NMO, MUTE, AGC, STACK).

Всього було виконано 3 аналізи кінематичних поправок.

17. На закінчення обробки виконувалась пост-стек часова міграція Кірхгофа 2D сейсмічних розрізів (MIGTX). 